\title{
(wellness and mattering: the role of holistic factors in job satisfaction
}

\author{
Kathleen M. Connolly \\ Jane E. Myers
}

\begin{abstract}
A study was conducted with 82 employees in varied positions to determine the variance in job satisfaction that could be accounted for by holistic wellness and mattering. Results of regression analyses revealed that both wellness and mattering contributed significantly to the variance in job satisfaction; however, wellness was the stronger predictor. When block variables such as age and job tenure were held constant, the contributions of wellness and mattering to job satisfaction were not significant.
\end{abstract}

Job satisfaction, defined as the extent to which individuals are satisfied with their jobs or how they feel about different aspects of their jobs (Cranny, Smith, \& Stone, 1992), is the most frequently studied concept in organizational behavior research (Spector, 1997). The importance of work to individuals and to society overall suggests the need to ensure that as workers, individuals reap the economic, psychological, and social benefits of work and that they are protected from the consequences of dissatisfaction with work, including increased physical and psychological illness (Herr \& Cramer, 1996). In fact, given the relationship between job satisfaction and employee health, the study and optimization of job satisfaction is a social responsibility (Spector, 1997). However, as workers become more removed from the ability to make meaning through their work, the opportunity to experience job satisfaction becomes more difficult (Fox, 1994).

Satisfaction with one's work has been found to be related to a myriad of physical, psychological, demographic or situational, and workplace variables (Cranny et al., 1992). For example, individuals who reported being satisfied with their jobs experienced fewer physical and psychosomatic symptoms (Fox, Dywer, \& Ganster, 1993; O'Driscoll \& Beehr, 1994). Lack of satisfaction with one's work has been associated with anxiety (Jex \& Gudanowski, 1992; Spector, Dwyer, \& Jex, 1988), depression (Bluen, Barling, \& Burns, 1990), and poor physical and psychological health (Jex \& Gudanowski, 1992; Lee, Ashford, \& Bobko, 1990). Diverse variables that have been shown to affect job satisfaction, both positively and negatively, include intelligence (Ganzach, 1988); job level, tenure, and pay grade (Chet, Ryan, Schmeider,

Kathleen M. Connolly, Acumeans, Inc., Charlotte, North Carolina, and the Department of Counseling. Special Education, and Child Development, University of North Carolina at Charlotte; Jane E. Myers, Department of Counseling and Educational Development, University of North Carolina at Greensboro. Correspondence concerning this article should be sent to Kathleen M. Connolly, 218B East Tremont Avenue, Charlotte, NC 28203 (e-mail: kmc@acumeans.com). 
Parra, \& Smith, 1998); employee empowerment (Kirkman \& Rosen, 1997); gender (Voyandoff, 1980); and perceived job stress (DeFrank \& Ivancevich, 1998). Whether or not individuals received feedback from their supervisors and the quality of that feedback have also been found to shape the experience of job satisfaction (Hackman $\&$ Oldham, 1980). The variety and nature of skills that employees perform have been shown to predict job satisfaction (Hackman \& Oldham, 1980; Voyandoff, 1980) whereas studies investigating age and job satisfaction have produced inconsistent results. These findings suggested the need to examine the aging process and job satisfaction rather than to focus simply on chronological age (Bernal, Snyder, \& McDaniel, 1998). On the basis of an extensive review of empirical studies relating job stressors to affective, health, and performance outcomes, Spector (1997) concluded that the optimization of job satisfaction is an important means of enhancing employees' psychological health and overall wellness.

Wellness, defined by Archer, Probert, and Gage (1987) as "the process and state of a quest for maximum human functioning that involves the mind, body, and spirit" (p. 311), is not defined solely by the absence of disease but also by the presence of physical, psychological, and spiritual well-being (Millar \& Hull, 1997; Myers, 1992; Witmer \& Sweeney, 1992). Although these definitions are holistic in nature, the application of wellness principles in business and industry settings focuses primarily on physical wellness (Bennett \& Lehman, 1997; Mazloff, 1998). Thus, employers equate wellness with physical health, ignoring, in a sense, the importance of other aspects of functioning that contribute to a sense of well-being and consequent work and life satisfaction (Csiernik, 1995).

Dollarhide (1997) suggested that there is a need for counselors to help individuals integrate work and life in order to encourage them to develop a deeper sense of meaning in both areas, thereby improving overall life satisfaction. Without meaning, "People learn they are not needed in the universe. Feeling unneeded, in turn, engenders self-hatred and the deadening of the self found in alcohol and drug abuse, crime that leads to prison, and other forms of self-punishment" (Fox, 1994, p. 60). The importance of being needed, of being important to others, and of feeling that others are interested in what individuals say and do have been referred to as "mattering" (Rosenberg \& McCullough, 1981). Persons who perceive that they matter are more likely to report feeling significant and to having a sense of belonging to society in general (Amundson, 1993; DeForge \& Barclay, 1997; Gossett, Cuyjet, \& Cockriel, 1998). Moreover, employees' perceptions of whether they matter to their supervisors, their organization, and other aspects of their work setting may be related to increased productivity and job satisfaction (Schlossberg, 1997). To date, the correspondence between mattering and job satisfaction remains hypothetical because an empirical relationship has not been established.

Even after years of organizational development research on job satisfaction, there remains a need to identify strategies for enhancing job satisfaction of individuals across the life span. Two variables that have been examined in recent literature and that may have a significant relationship to job satisfaction-holistic wellness and mattering-have not been studied. Therefore, the purpose of this study was to ex- 
amine the relationship between these variables. The following research questions provided a foundation for the study: To what extent can the variance in job satisfaction be accounted for by wellness and mattering? When other established predictors of job satisfaction (e.g., age, ethnicity, job tenure, education, skill variety, and feedback) are held constant, to what extent can the variance in job satisfaction be accounted for by wellness and mattering?

\section{METHOD}

The population of interest in this study included employees in business and industry settings. Volunteer participants were recruited through several businesses in the midwestern and southeastern United States through personal contacts with human resources departments. Each participant completed, during work time, a packet of paper-and-pencil instruments that required between 25 and 40 minutes to complete.

\section{Participants}

One hundred and thirty packets were distributed by mail to management staff in participating organizations; the managers then distributed the packets to employees to complete and return individually. Although 83 packets were returned, one was unusable because of missing data. Thus, only data from 82 respondents were included in the analyses, resulting in a response rate of $63 \%$. Of the 82 respondents, $55 \%(n=45)$ were women and $45 \%(n=37)$ were men. Eighty-two percent $(n=67)$ of the respondents reported their ethnic/cultural background as Caucasian, and the remaining 18\% were ethnic minorities, primarily African American (10\%). Approximately $60 \%(n=49)$ of the respondents reported being married or having a partner, $28 \%(n=23)$ were single, and $11 \%(n=9)$ were divorced. The respondents ranged in age from 21 to 62 years, with a mean age of $38.2(S D=10.33)$. The mean years of schooling reported was $14.78(S D=2.39)$.

The average job tenure or length of time participants were employed in their current positions was 4.89 years $(S D=5.86)$. Participants' positions in their respective organizations included customer service representative $(27 \%)$; manufacturing machine operator $(21 \%)$; accountant $(10 \%)$; city employees, such as planners and inspectors (10\%); and miscellaneous positions, such as clerical, sales, truck drivers, and social workers $(32 \%)$.

\section{Instrumentation}

The instrumentation for this study consisted of four measures: the Wellness Evaluation of Lifestyle (WEL; Myers, Sweeney, \& Witmer, 2000), the General Mattering Scale (GMS; Marcus, 1991), the Job Descriptive Index (JDI; Balzer et al., 1997), and a demographic information form.

The WEL (Myers et al., 2000). The WEL was designed to measure functioning along five life tasks that reflect Adler's theory of individual psychology (see Dreikurs, 
1954; Myers et al., 2000): spirituality, work, leisure, friendship, and love. The WEL consists of 105 statements (e.g., "I am an active person") to which respondents reply on a 5-point Likert-type scale that ranges from strongly agree to strongly disagree. Although the instrument may be scored according to five major subscales and 12 additional scales, only the Total Wellness score was used in this study. That score is obtained by summing scores for the individual items, providing a measure of holistic wellness.

The WEL has been normed on more than 3,500 persons who represent developmental stages across the life span. Test-retest reliabilities range between .90 and .96 for all scales, and internal consistency alpha coefficients range between .60 and .90 (Hattie, Myers, \& Sweeney, in press; Myers et al., 2000). Factor analysis and multiple studies using the WEL in combination with other measures have established both convergent and divergent validity for the WEL scales (Hattie et al., in press).

The GMS (Marcus, 1991). The GMS is composed of five items that are statements describing perceptions of relationships with others (e.g., "How important do you feel you are to other people?"). Respondents use a 4-point Likert format ranging from $4=$ very much to $\mathrm{l}=$ not at all to respond to each item. Scores are sums of individual item responses. Higher scores reflect greater individual perceptions of mattering.

DeForge and Barclay (1997), using a sample of 199 homeless men from a shelter in Baltimore, Maryland, reported a Cronbach alpha of .85 for the GMS. For the current study, the GMS was factor analyzed before we examined the research questions. Item 5 ("How much do you feel others depend on you?") was removed from the scale before data were analyzed because the factor loading of this item (.60) on the General Mattering factor was significantly lower than the loading for the other four items, which ranged from .80 to .88 . The resulting score range was, thus, 4 to 16 .

The JDI (Balzer et al., 1997). The JDI is the most widely used measure of job satisfaction (Buckley, Carraher, \& Cote, 1992) and is designed to be a multifaceted measure that can be used with a wide range of workers. The JDI consists of five scales that are reflective of common facets of job satisfaction, including Work on Present Job, Present Pay, Opportunities for Promotion, Supervision, and Coworkers. Along with the original five scales on the JDI, Balzer et al. recently added a Job-in-General scale (JIG) as a direct measure of overall job satisfaction. The JIG scale was used to measure overall job satisfaction in this study.

Balzer et al. (1997) reported a Cronbach alpha of .92 for the JIG. Convergent validity has been demonstrated by correlations with other global measures of satisfaction such as the Brayfield and Rothe (1951) Index of Job Satisfaction. These correlations ranged from .66 to .80 (Balzer et al., 1997).

\section{Data Analyses}

Frequencies and alpha coefficients were computed for each scale. We used a set of variables that have been established in the job satisfaction literature as significantly contributing to the variance in job satisfaction to investigate the degree to which the independent variables (i.e., wellness and mattering) accounted for a sig- 
nificant increase in the variance of the dependent variable job satisfaction, given the variance already accounted for by the block variables. The set of variables in the block were age, ethnicity, job tenure, education (in years), skill variety, and feedback. Due to small sample sizes, separate analyses on the basis of race and gender were not computed.

\section{RESULTS}

Means, standard deviations, score ranges, and alpha coefficients for all scales are provided in Table 1. The range of scores for the WEL and GMS were somewhat less than the possible range for both instruments, whereas scores for the JIG included the full range possible (i.e., 0-54). Alpha coefficients ranged from .83 for the WEL to .90 for the JIG.

The first research question asked whether wellness and mattering would predict a significant proportion of the variance in job satisfaction. Results of the regression analyses indicated that wellness and mattering, together, did predict a significant proportion of the variance in job satisfaction, $R^{2}=.10, F(2,81)=4.43, p=.01$. Further analysis of the standardized regression coefficients revealed that only wellness predicted a significant proportion of the variance in job satisfaction, $\beta=.24, t(2,81)$ $=2.09, p=.03$.

Positive, significant relationships were found between job satisfaction and mattering $(r=.22, p<.05)$ and between job satisfaction and wellness $(r=.29, p<.01)$. In addition, a significant, positive correlation was found between the independent variables wellness and mattering $(r=.37, p<.01)$. A correlation between the independent variables is indicative of collinearity. When collinearity is present, the estimates of the regression coefficients can be misleading. However, according to Pedhazur (1997), collinearity is problematic when correlations between independent variables are high; however, there is no agreement on what constitutes "high." Given the small-to-moderate magnitude of the correlation between wellness and mattering, collinearity is not likely to threaten the interpretation of the regression coefficients. Therefore, the outcome of the regression analysis was positive in that wellness and mattering significantly contributed to the prediction of job satisfaction, with wellness being a stronger predictor.

\section{TABLE 1}

\section{Descriptive Information and Alpha Coefficients for All Instruments}

\begin{tabular}{lccccc}
\hline \hline Scale & $\boldsymbol{M}$ & SD & Range & $\begin{array}{c}\text { Possible } \\
\text { Range }\end{array}$ & $\alpha$ Coefficient \\
\hline WEL & 75.67 & 7.25 & $53-91$ & $20-100$ & .83 \\
GMS & 12.90 & 2.50 & $7-16$ & $4-16$ & .87 \\
JIG & 43.29 & 9.24 & $0-54$ & $0-54$ & .90 \\
\hline
\end{tabular}

Note. WEL $=$ Wellness Evaluation of Lifestyle scale; GMS = General Mattering Scale; JIG $=$ Job-in-General scale. 
Question 2 asked whether wellness and mattering would predict a significant proportion of the variance in job satisfaction after accounting for other established predictors of job satisfaction. Age, job tenure, education, skill variety, and feedback were entered into the regression equation, followed by wellness and mattering. The results of the analyses are presented in Table 2.

The block variables alone were found to predict a significant proportion of the variance in job satisfaction, $R^{2}=.34, F(5,81)=8.00, p=.001$. However, when wellness and mattering were added to the equation, they did not increase $R^{2}$ by a statistically significant amount, $\Delta R^{2}=.02, F(7,81)=.83, p=.43$.

To determine which variables in the regression equation contributed significantly to the prediction of job satisfaction, the regression coefficients, or standardized beta weights, were examined. In the equation, including the block, wellness, and mattering, only skill variety contributed a statistically significant proportion to the variance of job satisfaction, $\beta=.49, t(7,81)=4.37, p=.001$ (see Table 2 ). These results suggested that wellness and mattering did not significantly contribute to the prediction of job satisfaction over and above the other established predictors (i.e., age, job tenure, education, skill variety, and feedback). Moreover, skill variety accounted for the majority of the variance in job satisfaction, suggesting that it is the strongest predictor variable in the equation.

\section{DISCUSSION}

The purpose of this study was to determine the extent to which the variance in job satisfaction could be accounted for by wellness and mattering. The first research question examined the relationship between the three variables (i.e., job satisfaction, wellness, and mattering) using regression analysis; the second research questioned examined the same relationships using regression analysis while holding constant a series of block variables determined in the literature to have a significant positive relationship with the dependent variable. The results of the first analysis

\section{TABLE 2}

\section{Summary of Multiple Regression Analyses for Predicting Job Satisfaction Given the Established Predictors $(n=82)$}

\begin{tabular}{|c|c|c|c|c|c|c|}
\hline Variable & $\beta$ & $t$ & $R^{2}$ & $F$ & $\Delta R^{2}$ & $F$ \\
\hline Block & & & .34 & $8.00^{\circ}$ & & \\
\hline Skill variety & .49 & $4.37^{*}$ & & & & \\
\hline Feedback & .04 & 0.39 & & & & \\
\hline Education & -.76 & -0.77 & & & & \\
\hline \multirow{2}{*}{\multicolumn{7}{|c|}{ Block with wellness }} \\
\hline & & & & & & \\
\hline and mattering & & & .36 & $5.93^{\circ}$ & .02 & .83 \\
\hline Wellness & .13 & 1.25 & & & & \\
\hline Mattering & -.00 & -0.64 & & & & \\
\hline
\end{tabular}

$\cdot p<.001$. 
provided support for both wellness and mattering as predictors of job satisfaction, with wellness being the stronger predictor. However, the second regression analysis revealed that wellness and mattering did not significantly contribute to the variance in job satisfaction over and above the other established predictors (i.e., age, job tenure, skill variety, and feedback). Positive, significant relationships were found between job satisfaction and mattering and between job satisfaction and wellness.

As noted earlier, most studies of job satisfaction and most work site wellness programs emphasize the physical aspects of wellness rather than the more inclusive factors found in holistic wellness models. The finding in this study that holistic wellness predicted a significant proportion of the variance in job satisfaction suggests a need for giving attention to additional factors of wellness in promoting satisfaction with work. Although an argument can be made that increased wellness promotes higher job satisfaction, employers who are funding work site wellness programs require more specific information in order to develop effective outcome-based interventions to meet employees' holistic wellness needs. Studies are needed that focus on facets of wellness (e.g., spirituality, leisure, friendship, love) in relation to job satisfaction to provide a basis for program planning.

Because mattering explained only a small proportion of the variance in job satisfaction $\left(R^{2}=.048\right)$, the hypothesized relationship between mattering and job satisfaction was only minimally supported in this study. The finding that wellness and mattering, together, did not predict job satisfaction over and above other established predictors was unexpected. Possible reasons for this finding include the sample size, which might have been too low to detect differences that actually existed; it is also possible that the measures used lacked sufficient sensitivity to detect actual differences. On the other hand, it may be that other factors are of such importance to job satisfaction that wellness and mattering are insignificant by comparison. The latter conclusion seems to be counterintuitive based on the literature reviewed for this study. Therefore, further research is needed with larger and more diverse samples to confirm or refute the current findings.

Although the overall sample size for this study was small, the participants represented a variety of positions in business and industry, which is a population that does not typically participate in counseling research. Furthermore, to our knowledge, this was the first study to date to explore the relationships between holistic wellness, mattering, and job satisfaction. The discovery of such relationships informs an important dialogue about the relationships between work and wellness and between work and the ability to make meaning in life through work. Consequently, further research is needed to verify, refute, or extend the current findings. In particular, research with larger samples that allows within-group comparisons according to variables such as age, gender, and ethnicity is needed. Further specificity regarding the mattering variable is needed; perhaps this variable should be assessed with measures that are more extensive than is the GMS.

The task of work is pervasive throughout the life span, and the degree to which individuals experience or fail to experience satisfaction with work shapes their level of health and well-being. Helping clients cope with their role as worker and the 
increasingly complex nature of work is no small task. Counselors providing career, employment, or employee assistance counseling may use the results of the present study to develop more comprehensive services, including work site wellness programs, that integrate holistic wellness and mattering as the basis for interventions that can ultimately enhance job satisfaction. The Wheel of Wellness model and the WEL (Myers et al., 2000), which are based in counseling theory, can be used as a foundation for wellness interventions. Similarly, the GMS, which is short yet psychometrically sound, can be used to assess perceptions of mattering in the workplace and to develop interventions to help employees feel more connected to others in their environment. Overall, the results of our study underscore the need for counselors to design, implement, and evaluate interventions that focus on individual psychological variables as important bases for enhancing job satisfaction.

\section{REFERENCES}

Amundson, N. E. (1993). Mattering: A foundation for employment counseling and training. Journal of Employment Counseling, 30, 146-152.

Archer, J., Probert, B. S., \& Gage, L. (1987). College students' attitudes toward wellness. Journal of College Student Personnel, 28, 311-317.

Balzer, W. K., Kihm. J. A., Smith, P. C., Irwin, J. L., Bachiochi, P. D., Robie, C., et al. (1997). Users' manual for the Job Descriptive Index and the Job in General scales. Bowling Green, $\mathrm{OH}$ : Bowling Green State University.

Bennett, G. B., \& Lehman, W. K. (1997). Employee views of organizational wellness and the EAP: Influence on substance use, drinking climates, and policy attitudes. Employee Assistance Quarterly, 13, 55-71.

Bernal, D., Snyder, D., \& McDaniel, M. (1998). The age and job satisfaction relationship: Does its shape and strength still evade us? Journals of Gerontology: Series B: Psychological Sciences and Social Sciences, 53B, 287-293.

Bluen, S. D., Barling. J., \& Burns, W. (1990). Predicting sales performance, job satisfaction, and depression by using the achievement strivings and impatience-irritability dimensions of type A behavior. Journal of Applied Psychology, 75, 212-216.

Brayfield, A. H., \& Rothe, H. F. (1951). An index of job satisfaction. Journal of Applied Psychology, 35, 307-311.

Buckley, M. R., Carraher, S. M., \& Cote, J. A. (1992). Measurement issues concerning the use of inventories of job satisfaction. Educational and Psychological Measurement, 52, 529-543.

Chet, R., Ryan, A., Schmeider, R. A., Parra, L. F., \& Smith, P. C. (1998). The relation between job level and job satisfaction. Group and Organization Management, 23, 470-495.

Cranny, C. J., Smith, P. C., \& Stone, E. F. (Eds.). (1992). Job satisfaction: How people feel about their jobs and how it affects their performance. Lexington. MA: Lexington Books.

Csiernik, R. (1995). Wellness, work and employee assistance programming. Employee Assistance Quarterly, 11(12), 1-13.

DeForge, B. R.. \& Barclay, D. M. (1997). The internal reliability of a general mattering scale in homeless men. Psychological Reports, 80, 429-430.

DeFrank, R. S., \& Ivancevich, J. M. (1998). Stress on the job: An executive update. The Academy of Management Executive, 12, 55-66.

Dollarhide, C. T. (1997). Counseling for meaning in work and life: An integrated approach. Journal of Humanistic Education and Development, 35, 178-187.

Dreikurs, R. (1954). Fundamentals of Adlerian psychology. Chicago: Alfred Adler Institute.

Fox. M. (1994). The reinvention of work: A new vision of livelihood for our time. San Francisco: Harper. 
Fox, M. L., Dwyer, D. J., \& Ganster, D. C. (1993). Effects of stressful job demands and control on physiological and attitudinal outcomes in a hospital setting. Academy of Management Journal, 36, 289-318.

Ganzach, Y. (1988). Intelligence and job satisfaction. Academy of Management Journal, 41, 526-539.

Gossett, B. J., Cuyjet, M. J., \& Cockriel, I. (1998). African Americans' perception of marginality in the campus culture. College Student Journal, 32, 22-32.

Hackman, J. R., \& Oldham, G. R. (1980). Work redesign. Reading, MA: Addison-Wesley.

Hattie, H. A., Myers, J. E., \& Sweeney, T. J. (in press). A multidisciplinary model of wellness: The development of the Wellness Evaluation of Lifestyle. Journal of Counseling \& Development.

Herr, E. L., \& Cramer, S. H. (1996). Career guidance and counseling through the life span: Systematic approaches (5th ed.). HarperCollins.

Jex, S. M., \& Gudanowski, D. M. (1992). Efficacy beliefs and work stress: An exploratory study. Journal of Organizational Behavior, 13, 509-517.

Kirkman, B. L., \& Rosen, B. (1997). A model of teamwork empowerment. Research in Organizational Change and Development, 10, 131-167.

Lee, C., Ashford, S. J., \& Bobko, P. (1990). Interactive effects of "type" A behavior and perceived control on worker performance, job satisfaction, and somatic complaints. Academy of Management Journal, 33, 870-881.

Marcus, F. M. (1991). Mattering: Its measurement and theoretical significance. Unpublished manuscript.

Mazloff. D. (1998). The importance of strategic worksite health promotion: A study of employee knowledge and employee assistance program promotion. Employee Assistance Quarterly, 14, $47-65$.

Millar, J. S., \& Hull, C. (1997). Measuring human wellness. Social Indicators Research, 40, 147-158.

Myers, J. E. (1992). Wellness, prevention, development: The cornerstone of the profession. Journal of Counseling \& Development, 71, 136-139.

Myers, J. E. (1996). Manual for the Wellness Evaluation of Lifestyle. Greensboro, NC: Author.

Myers, J. E., Sweeney, T. J., \& Witmer, J. M. (2000). The wheel of wellness counseling for wellness: A holistic model for treatment planning. Journal of Counseling \& Development, 78, 251-266.

Myers, J. E., Witmer, J. M., \& Sweeney, T. J. (1994). The WEL workbook. Palo Alto: MindGarden Press.

O’Driscoll, M. P., \& Beehr, T. A. (1994). Supervisor behaviors, role stressors and uncertainty as predictors of personal outcomes for subordinates. Journal of Organizational Behavior, 15, 141-155.

Pedhazur, E. J. (1997). Multiple regression in behavioral research. Orlando, FL: Harcourt Brace.

Rosenberg, M., \& McCullough, B. C. (1981). Mattering: Inferred significance and mental health among adolescents. Research in Community Mental Health, 2, 163-182.

Schlossberg, N. K. (1997). A model of worklife transitions. In R. Feller \& G. Walz (Eds.), Career transitions in turbulent times: Exploring work, learning and careers (pp. 93-103). Greensboro, NC: ERIC Clearinghouse on Counseling and Student Services.

Spector, P. E. (1997). Job satisfaction: Application, assessment, causes and consequences. Thousand Oaks, CA: Sage.

Spector, P. E., Dwyer, D. J., \& Jex, S. M. (1988). Relation of job stressors to affective, health, and performance outcomes: A comparison of multiple data sources. Journal of Applied Psychology; 73, 11-19.

Voyandoff, P. (1980). Perceived job characteristics and job satisfaction among men and women. Psychology of Women Quarterly, 5, 177-185.

Witmer, J. M., \& Sweeney, T. J. (1992). A holistic model for wellness and prevention over the life span. Journal of Counseling \& Development, 71, 140-148. 